Journal Club

Editor's Note: These short reviews of recent JNeurosci articles, written exclusively by students or postdoctoral fellows, summarize the important findings of the paper and provide additional insight and commentary. If the authors of the highlighted article have written a response to the Journal Club, the response can be found by viewing the Journal Club at www.jneurosci.org. For more information on the format, review process, and purpose of Journal Club articles, please see http://jneurosci.org/content/ preparing-manuscript\#journalclub.

\title{
Potential Effects of Aspirin on Lysosomal Biogenesis and Amyloid- $\beta$ Clearance: An Old Drug and Novel Insights in Alzheimer's Disease Therapy
}

\author{
Helen M. Melo \\ Institute of Medical Biochemistry Leopoldo de Meis, Federal University of Rio de Janeiro, Rio de Janeiro, RJ, Brazil, 21941-902 \\ Review of Chandra et al.
}

\begin{abstract}
Alzheimer's disease $(\mathrm{AD})$ is a complex, multifactorial, progressive neurodegenerative disorder and the most common form of dementia in the elderly, affecting $>47$ million patients worldwide and expected to affect 131 million by 2050 (Prince et al., 2016). Unfortunately, even with numerous advances in understanding $\mathrm{AD}$ pathophysiology over the years, there is currently no available cure or drug that prevents disease progression.

Like other neurodegenerative disorders, $\mathrm{AD}$ is associated with the presence of aberrant protein aggregates in the brain. The two major histopathological hallmarks of $\mathrm{AD}$ are amyloid plaques, which are extracellular deposits of insoluble forms of amyloid- $\beta$ peptide $(\mathrm{A} \beta)$, and neurofibrillary tangles, which are intracellular aggregates of hyperphosphorylated microtubule-associated tau protein (Masters et al., 2015).

Since the original description by Alois Alzheimer, and reinforced by the "amyloid hypothesis" of $\mathrm{AD}$, increasing amounts of soluble and insoluble $A \beta$ peptide in several brain areas has been considered central to the pathogenesis of $\mathrm{AD}$. In particular, $\mathrm{A} \beta$
\end{abstract}

Received Sept. 4, 2018; revised Nov. 2, 2018; accepted Nov. 14, 2018.

I thank the Fundação de Amparo à Pesquisa do Estado do Rio de Janeiro for the postdoctoral fellowship.

The authors declare no competing financial interests.

Correspondence should be addressed to Dr. Helen M. Melo, Av. Carlos

Chagas Filho, 373, Room H2-019, CCS, Cidade Universitária, Rio de Janeiro,

RJ, Brazil, 21941-902. E-mail: maciqueira@bioqmed.ufrj.br.

https://doi.org/10.1523/JNEUROSCI.2283-18.2018

Copyright $\odot 2019$ the authors $\quad 0270-6474 / 19 / 390197-02 \$ 15.00 / 0$ deposition affects areas of the cerebral cortex and hippocampus, resulting in cognitive symptoms, such as learning and memory deficits, as well as some noncognitive effects (Selkoe and Hardy, 2016). Although rare, dominantly inherited genetic mutations promote $\mathrm{A} \beta$ accumulation by accelerating cleavage of $\beta$-amyloid precursor protein (APP) and thus increasing $\mathrm{A} \beta$ production, sporadic risk factors are thought to promote accumulation of toxic $\mathrm{A} \beta$ monomers, oligomers, insoluble fibrils, and plaques by impairing $A \beta$ clearance mechanisms (Selkoe and Hardy, 2016).

The autophagy-lysosome system is an essential and highly regulated intracellular degradation pathway by which abnormal protein aggregates are removed from cells. Autophagosomes sequester these aggregates and transport them to lysosomes for degradation (He and Klionsky, 2009). In $\mathrm{AD}$, dysfunction in autophagy and lysosomal function compromises A $\beta$ clearance. Importantly, the brain of $\mathrm{AD}$ patients and transgenic mice expressing $\mathrm{AD}$-linked mutations (APP/PS1) exhibit accumulation of autophagic vacuoles in dystrophic neurites and a reduction in lysosomal degradation capacity (Yu et al., 2004; Nixon et al., 2005). Moreover, amyloid plaque deposition and accumulation impair the retrograde axonal transport of lysosome precursors, inducing local accumulation of immature lysosomes containing low levels of lysosomal pro- teases, and thus reduced proteolytic capacity (Gowrishankar et al., 2015). Therefore, improvement in $\mathrm{A} \beta$ clearance is an attractive disease-modifying strategy for $\mathrm{AD}$ therapy, and lysosomal function is a potential target to delay or even halt $\mathrm{AD}$.

A recent report published in The Journal of Neuroscience (Chandra et al., 2018) has investigated the effects of low doses of aspirin, a classic and widely used nonsteroidal anti-inflammatory drug, in astrocytic lysosomal biogenesis and $\mathrm{A} \beta$ clearance. Chandra et al. (2018) demonstrated that low doses of aspirin increased LysotrackerRed signals and other lysosomal markers, such as lysosome-associated membrane protein 2 (LAMP2), in mouse primary astrocytes, indicating an improvement in lysosome biogenesis. Importantly, the boost in lysosome number was accompanied by greater lysosome function, assessed by catalytic activity of cathepsins and TPP1 (Chandra et al., 2018), two lysosomal proteases that facilitate $\mathrm{A} \beta$ degradation (Wang et al., 2012; Solé-Domènech et al., 2018). In addition, Chandra et al. (2018) observed an increased number of autophagic vesicles in different stages of maturation in aspirintreated primary astrocytes. Together, these results shed light on the potential usefulness of aspirin in reversing brain lysosomal dysfunction and related diseases.

To clarify the role of aspirin in lysosomal biogenesis, Chandra et al. (2018) examined 
whether this drug affected the major regulator of the autophagy-lysosomal system, the transcription factor EB (TFEB). Aspirin increased Tfeb mRNA and TFEB protein levels surrounding the nucleus in mouse primary astrocytes. In addition, LAMP2 was upregulated in astrocytes after aspirin exposure, and this was abolished by TFEB silencing (Chandra et al., 2018). Overall, these findings suggested upregulation of TFEB as a key mechanism in aspirin-induced lysosomal biogenesis.

Recently, the presence of the peroxisome proliferator responsive element (PPRE) in the Tfeb gene promoter has been identified as a potential site of TFEB regulation by $\operatorname{PPAR} \alpha$, a transcription factor that regulates numerous genes. This regulatory mechanism has been proposed as a potential therapeutic target to improve lysosome function in lysosomal storage disorders (Ghosh et al., 2015; Ghosh and Pahan, 2016). Accordingly, using a double labeling of PPAR $\alpha$ and GFAP Chandra et al. (2018) showed that aspirin induced nuclear translocation of PPAR $\alpha$ in primary astrocytes. Importantly, aspirin-induced localization of PPAR $\alpha$ in the nucleus and perinuclear space has been related to an increased DNA-binding activity of PPAR $\alpha$ to PPRE site on the Tfeb gene, observed through shifted DNA migration rate in an electrophoretic mobility shift assay (Chandra et al., 2018). These findings suggested that aspirin-induced TFEB upregulation and lysosomal biogenesis in astrocytes were modulated by increased PPAR $\alpha$ activation.

Chandra et al. (2018) investigated whether specifically activation of PPAR $\alpha$ would transcriptionally regulate $T f e b$ expression. Notably, astrocytes transfected with the pPPRE-luciferase construct showed a marked increase in the PPRE-driven luciferase activity after aspirin treatment, which is prevented by deletion of Ppara, but not the Pparb gene (Chandra et al., 2018). Similarly, using primary astrocytes transfected with a construct containing a mutated PPRE core sequence on the TFEB promoter, Chandra et al. (2018) observed a reduction in the TFEB-driven luciferase activity induced by aspirin. In line with these findings, $\operatorname{PPAR} \alpha$ antagonist (GW6471), unlike PPAR $\beta$ (GSK0660) or PPAR $\gamma$ (GW9662) antagonists, abolished aspirininduced Tfeb promoter-driven luciferase activity in primary astrocytes. Collectively, these results confirmed the specific role of $\operatorname{PPAR} \alpha$ in the aspirin-mediated transcriptional induction of the TFEB promoter (Chandra et al., 2018) and delineated a new pharmacological action for aspirin.
Finally, Chandra et al. (2018) explored how positive effects of aspirin in astrocytic lysosome biogenesis affect amyloid pathology in vivo. Oral administration of low doses of aspirin ( $2 \mathrm{mg} / \mathrm{kg}$ body weight/d; $1 \mathrm{month}$ ) increased PPAR $\alpha$ recruitment in hippocampal astrocytes of 5XFAD mice, an $\mathrm{AD}$ model that rapidly develops severe amyloid pathology. Notably, aspirin also induced higher levels of TFEB and LAMP2 in hippocampal astrocytes, indicating an improvement in lysosomal biogenesis in vivo.

Importantly, previous findings demonstrated that the activation of TFEB and increased lysosome number improved astrocytic $\mathrm{A} \beta$ clearance and reduced amyloid plaque load in the hippocampus of APP/PS1 mice (Xiao et al., 2014). Notably, Chandra et al. (2018) observed a remarkable reduction in $\mathrm{A} \beta$ peptide and plaque load in the hippocampus of 5XFAD mice treated with aspirin. Furthermore, in 5XFAD-Ppara-null mice, aspirin treatment was unable to lower $A \beta$ pathology, demonstrating the relevance of PPAR $\alpha$ activation in the antiamyloidogenic effects of aspirin. Nevertheless, it is possible that aspirin also stimulates nonamyloidogenic processing of APP in a PPAR $\alpha$-dependent manner in line with previous findings (Corbett et al., 2015).

A remaining question is how aspirin treatment and reduction in amyloid load might improve memory deficits, the main clinical characteristic of $\mathrm{AD}$, in transgenic mice. Recently, Patel et al. (2018) demonstrated that aspirin acted as a PPAR $\alpha$ ligand in the hippocampal neurons. Interestingly, this activity stimulated hippocampal plasticity via transcriptional activation of cAMP response element-binding protein and improved hippocampal plasticity and memory deficits in FAD5X mice, but not in FAD5X-Ppara-null mice. These findings indicate a positive pleiotropic action of aspirin in different pathological aspects of $\mathrm{AD}$ (Patel et al., 2018).

In conclusion, Chandra et al. (2018) have established a new function of aspirin in $\operatorname{PPAR} \alpha$-mediated upregulation of TFEB, leading to enhanced astrocytic lysosome biogenesis and function. Moreover, aspirininduced lysosome biogenesis was associated with improved $A \beta$ pathology in a mouse model of $\mathrm{AD}$. These data suggest a new use for aspirin, one of the most widely used medications in the world, for reducing amyloid pathology in $\mathrm{AD}$. This work should encourage further studies to assess how this old drug can contribute to the current challenge of treating $\mathrm{AD}$.

\section{References}

Chandra S, Jana M, Pahan K (2018) Aspirin induces lysosomal biogenesis and attenuates amyloid plaque pathology in a mouse model of Alzheimer's disease via PPAR $\alpha$. J Neurosci 38:6682-6699. CrossRef Medline

Corbett GT, Gonzalez FJ, Pahan K (2015) Activation of peroxisome proliferator-activated receptor $\alpha$ stimulates ADAM10-mediated proteolysis of APP. Proc Natl Acad Sci U S A 112:8445-8450. CrossRef Medline

Ghosh A, Pahan K (2016) PPARa in lysosomal biogenesis: a perspective. Pharmacol Res 103: 144-148. CrossRef Medline

Ghosh A, Jana M, Modi K, Gonzalez FJ, Sims KB, Berry-Kravis E, Pahan K (2015) Activation of peroxisome proliferator-activated receptor $\alpha$ induces lysosomal biogenesis in brain cells. J Biol Chem 290:10309-10324. CrossRef Medline

Gowrishankar S, Yuan P, Wu Y, Schrag M, Paradise S, Grutzendler J, De Camilli P, Ferguson SM (2015) Massive accumulation of luminal protease-deficient axonal lysosomes at Alzheimer's disease amyloid plaques. Proc Natl Acad Sci U S A 112:E3699-E3708. CrossRef Medline

He C, Klionsky DJ (2009) Regulation mechanisms and signaling pathways of autophagy. Annu Rev Genet 43:67-93. CrossRef Medline

Masters CL, Bateman R, Blennow K, Rowe CC, Sperling RA, Cummings JL (2015) Alzheimer's disease. Nat Rev Dis Primers 1:15056. CrossRef Medline

Nixon RA, Wegiel J, Kumar A, Yu WH, Peterhoff C, Cataldo A, Cuervo AM (2005) Extensive involvement of autophagy in Alzheimer disease: an immuno-electron microscopy study. J Neuropathol Exp Neurol 64:113-122. CrossRef Medline

Patel D, Roy A, Kundu M, Jana M, Luan CH, Gonzalez FJ, Pahan K (2018) Aspirin binds to $\operatorname{PPAR} \alpha$ to stimulate hippocampal plasticity and protect memory. Proc Natl Acad Sci 115: E7408-E7417. CrossRef Medline

Prince M, Comas-Herrera A, Knapp M, Guerchet M, Karagiannidou M (2016) World Alzheimer Report 2016: improving healthcare for people living with dementia. Coverage, quality and costs now and in the future. Alzheimer's Dis Int 1-140. Available at https://www.alz.co.uk/ research/world-report-2016.

Selkoe DJ, Hardy J (2016) The amyloid hypothesis of Alzheimer's disease at 25 years. EMBO Mol Med 8:595-608. CrossRef Medline

Solé-Domènech S, Rojas AV, Maisuradze GG, Scheraga HA, Lobel P, Maxfield FR (2018) Lysosomal enzyme tripeptidyl peptidase 1 destabilizes fibrillar $\mathrm{A} \beta$ by multiple endoproteolytic cleavages within the $\beta$-sheet domain. Proc Natl Acad Sci U S A 115:1493-1498. CrossRef Medline

Wang C, Sun B, Zhou Y, Grubb A, Gan L (2012) Cathepsin $\mathrm{B}$ degrades amyloid- $\beta$ in mice expressing wild-type human amyloid precursor protein. J Biol Chem 287:39834-39841. CrossRef Medline

Xiao Q, Yan P, Ma X, Liu H, Perez R, Zhu A, Gonzales E, Burchett JM, Schuler DR, Cirrito JR, Diwan A, Lee JM (2014) Enhancing astrocytic lysosome biogenesis facilitates $\mathrm{A} \beta$ clearance and attenuates amyloid plaque pathogenesis. J Neurosci 34:96079620. CrossRef Medline

Yu WH, Kumar A, Peterhoff C, Shapiro Kulnane L, Uchiyama Y, Lamb BT, Cuervo AM, Nixon RA (2004) Autophagic vacuoles are enriched in amyloid precursor protein-secretase activities: implications for $\beta$-amyloid peptide over-production and localization in Alzheimer's disease. Int J Biochem Cell Biol 36:2531-2540. CrossRef Medline 